Showa Univ. J. Med. Sci. 3(1), 41 46, June 1991

\title{
Original
}

\section{Maxillomandibular Fixation in Fractures of the Mandible}

\author{
Tibiriçá Berti Rodrigues ${ }^{1)}$, Hiromichi AKIzuki ${ }^{2)}$, Takashi OKada ${ }^{2)}$,

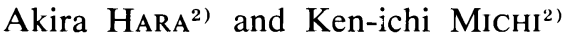

\begin{abstract}
This retrospective study of 59 patients with fractures of the mandible was undertaken to evaluate maxillomandibular fixation. Of the patients treated by rigid fixation, $63.3 \%$ achieved clinical union within 4 weeks. Fractures with no mobility were treated by semirigid fixation. Neither of these experienced any complication. It was concluded that most uncomplicated mandibular fractures need no more than 4 weeks of rigid fixation for clinical union, and semirigid fixation is indicated when there is no mobility at the fracture site.
\end{abstract}

Key words: maxillomandibular fixation, fracture, mandible

\section{Introduction}

There are many open reduction techniques for the management of mandibular fractures. The significance of these techniques is avoidance of maxillomandibular fixation ${ }^{1)}$. However the methods have disadvantages ${ }^{2}$.

Closed reduction remains a good choice for treatment of many mandibular fractures, and maxillomandibular fixation is often used $^{1,3-i)}$. Some consequent inconveniences are discomfort, frequent outpatient visits, weight loss, temporomandibular joint (TMJ) dysfunction, periodontal alteration, and social problems. To avoid those inconveniences many oral and maxillofacial surgeons have reconsidered the length of the maxillomandibular fixation period, and are opening their patients mouths early $3,6,8,10)$.

This retrospective study was undertaken in the First Department of Oral and Maxillofacial Surgery of the Showa University Dental School to evaluate the current tendency in duration of maxillomandibular fixation.

\section{Materials and Methods}

This study is based on the evaluation of 59 selected cases with mandibular fractures treated over the past 5 years in the First Department of Oral and Maxillofacial Surgery in the Showa University Dental School. All patients chosen were treated by closed reduction of their mandibular fractures. Angle, body, and synphysis fractures were selected for this study including condyle, ramus and alveolar associated fractures. Isolated condyle, ramus and alveolar fractures and cases with associated midface fractures were excluded. Also excluded were all mandibular fractures treated by open reduction using wire or a plate.

Semirigid fixation was used when there was no distraction or mobility at the fracture site and rigid fixation was used for mobile or distraction cases. The fracture site was checked

1) Department of Oral and Maxillofacial Surgery, Dental School-UFPel, Perotas, RS, Brazil.

2) First Department of Oral and Maxillofacial Surgery, Showa University School of Dentistry, 2-1-1 Kitasenzoku, Ohta-ku, Tokyo 145, Japan. 
for union once a week by clinical examination. If there was mobility at the fracture site, the rigid fixation was retained. If the fracture site was immobile, fixation was terminated.

\section{Results}

Patients ranged in age from 6 years to 63 years, with the largest single group in the 11 to 20 age range (Fig. 1). Most patients were in the age group of 11 to 30 years $(76.3 \%)$. About $78 \%$ of all fractures occurred in men.

Among the 59 cases, there were 97 fractures sites, an average of 1.6 fractures per patient. Single fractures occurred in 47.5 per cent; double fractures of the mandible occurred in 25 patients $(42.4 \%)$; triple fractures occurred in 6 patients. In this study, a comminuted fracture was considered to be a single fracture; 7 cases were classified as comminuted.

The angle was the most common fracture site reported $(30.9 \%)$, followed by synphysis $(28.9 \%)$, and body $(16.5 \%)$. In the associated fractures group, most occurred in the condyle region (Fig. 2).

Fifty-four patients were treated by local anesthesia $(91.5 \%), 2$ by general anesthesia and 3 did not undergo anesthesia. There were 26 patients were treated as outpatients and 33 as inpatients.

Immobilization was achieved with eyelet wires, described by Ueno ${ }^{11)}$, in 54 cases. A chin cap was used on 4 patients, and one patient received oral surgery brackets described by Yoshimasu et al. ${ }^{12)}$. In 7 patients $(11.9 \%)$ only elastic bands or a chin cap were applied for maxillomandibular fixation and, wire fixation was used in all others $(88.1 \%)$. Of the 59 patients, 11 developed complications (Table 1); 6 were diagnosed at the first examination (before fixation) and 5 after fixation release.

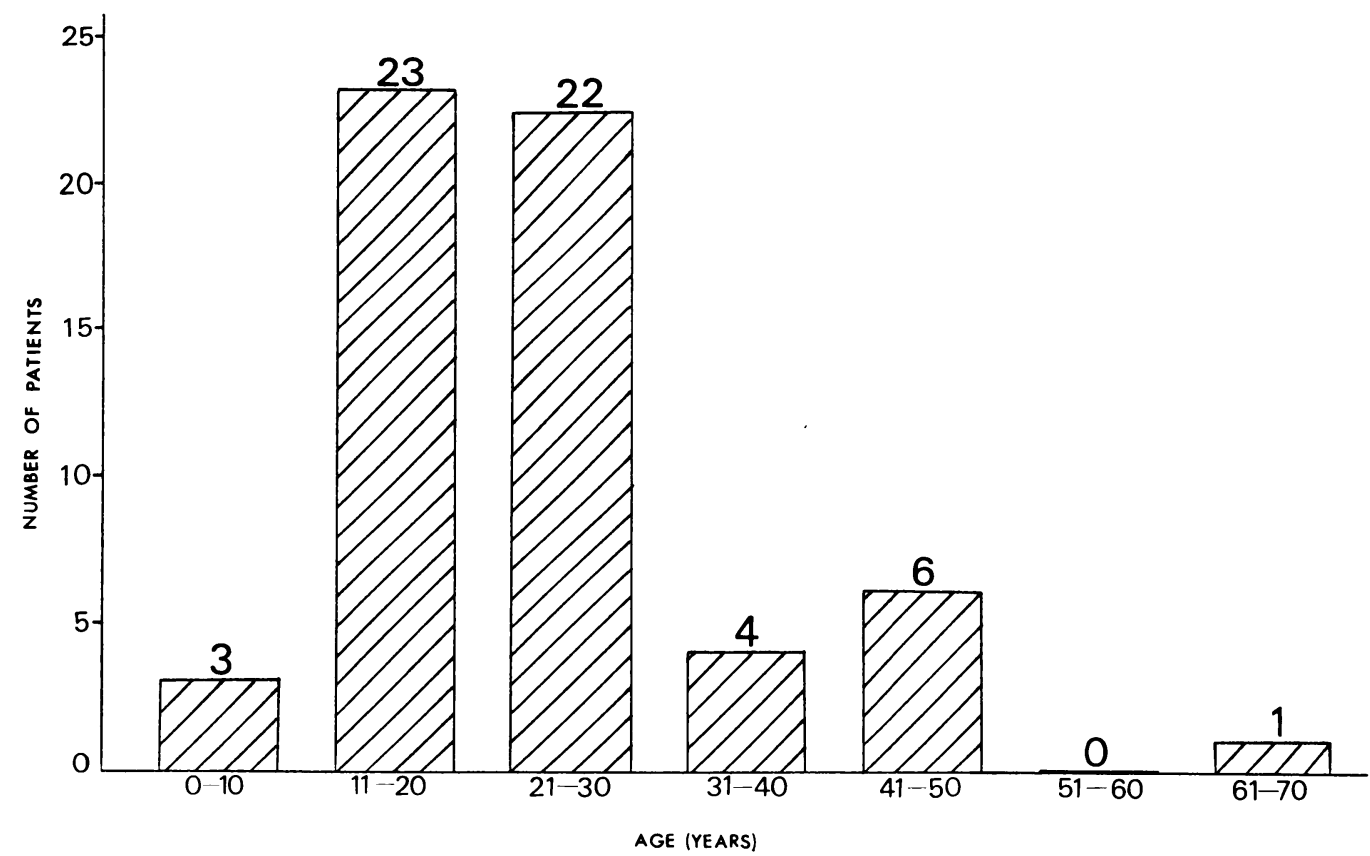

Fig. 1. Age distribution of 59 patients with mandibular fractures. 


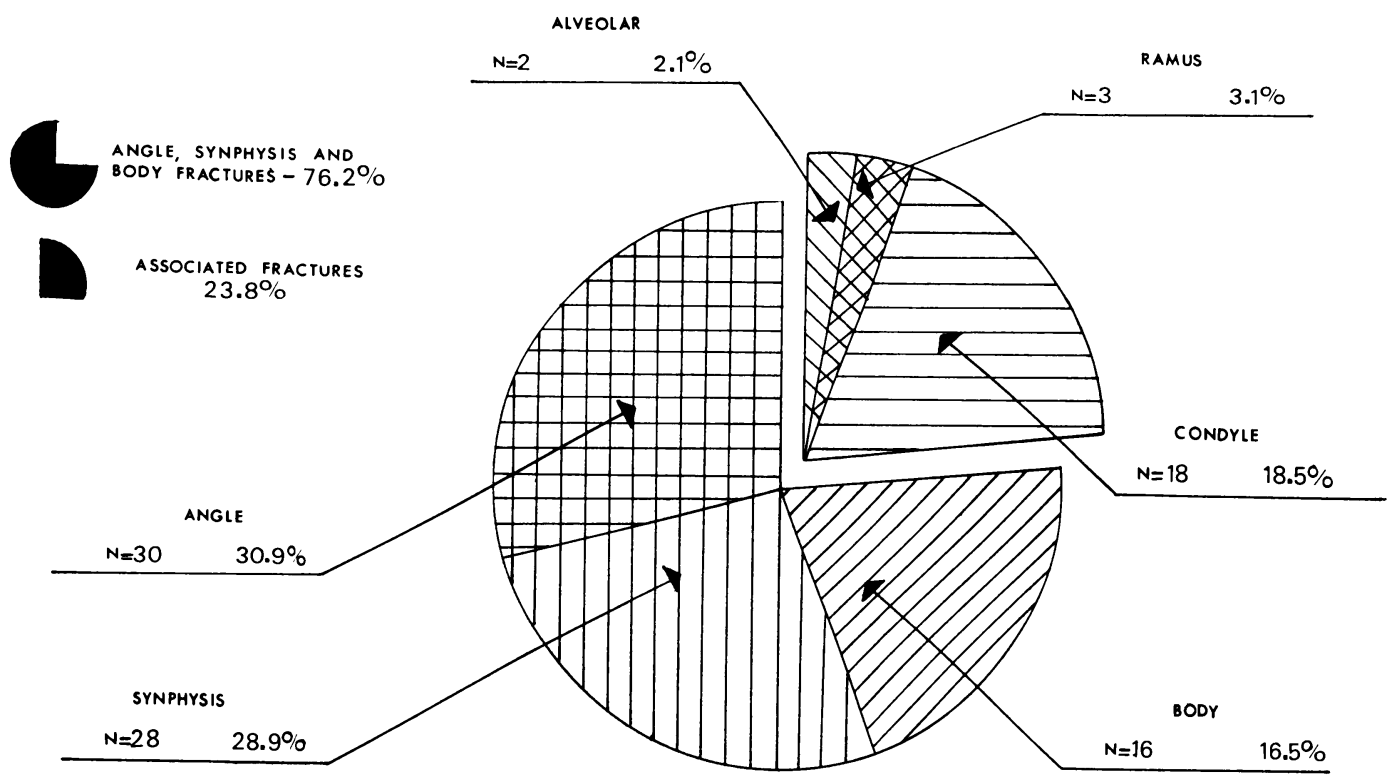

Fig. 2. Anatomic distribution of 97 mandibular fractures in 59 patients. $\mathrm{N}=$ number of cases.

Table 1. Complications with mandibular fractures.

\begin{tabular}{lcclc}
\hline \multicolumn{1}{c}{ Complications } & $\begin{array}{c}\text { Number of } \\
\text { patients }\end{array}$ & Percentage & Diagnosis time & Distribution (\%) \\
\hline Paresthesia & 5 & 45.4 & First examination & 6 cases (54.5) \\
Preoperative infection & 1 & 9.1 & First examination & \\
Malocclusion & 2 & 18.2 & After fixation release & \\
Malunion & 2 & 18.2 & After fixation release \\
TMJ symptoms & 1 & 9.1 & After fixation release & 5 cases (45.5) \\
\hline Total & 11 & 100 & - & 11 cases (100) \\
\hline
\end{tabular}

\section{1) Semirigid fixation group}

Seven patients received semirigid fixation treatment. Four patients were treated by chin cap, and elastic bands were applied to the eyelet wire in 3 patients. In this group all patients were men; 5 fractures were single, 2 were double, and there was no comminuted fracture. The duration of semirigid fixation ranged from 14 days to 53 days with an average of 27.1 days. There were no complications in this group (Table 2).

2) Rigid fixation group

In 51, patients rigid fixation was achieved with stainless steel wires applied to the eyelet wire, and wire was applied to the oral surgery brackets in one patient. Elastic bands were used in most cases to correct occlusion $(84.6 \%)$, and were then changed to wires.

Injuries resulting from 23 simple fractures, 23 double fractures, and 6 triple fractures of the mandible in this group (comminution at 7 fracture sites was considered as a simple fracture). There were 39 men and 13 women in this series (75\% and $25 \%$, respectively).

The duration of rigid fixation in the 52 patients ranged from 10 to 58 days with an 
Table 2. Postoperative complications related to maxillomandibular fixation.

\begin{tabular}{|c|c|c|c|c|}
\hline \multirow{2}{*}{ Treatment } & \multirow{2}{*}{$\begin{array}{c}\text { Number of } \\
\text { patients }\end{array}$} & \multicolumn{3}{|c|}{ Complications } \\
\hline & & Kind & Total & Percentage \\
\hline Semirigid fixation & 7 & - & 0 & 0 \\
\hline Rigid fixation (up to 4 weeks) & 35 & $\begin{array}{l}\text { Malocclusion-2 } \\
\text { Malunion-1 } \\
\text { TMJ symptoms-1 }\end{array}$ & 4 & 11.4 \\
\hline Rigid fixation (total) & 52 & $\begin{array}{l}\text { Malocclusion-2 } \\
\text { Malunion-2 } \\
\text { TMJ symptoms-1 }\end{array}$ & 5 & 9.6 \\
\hline
\end{tabular}

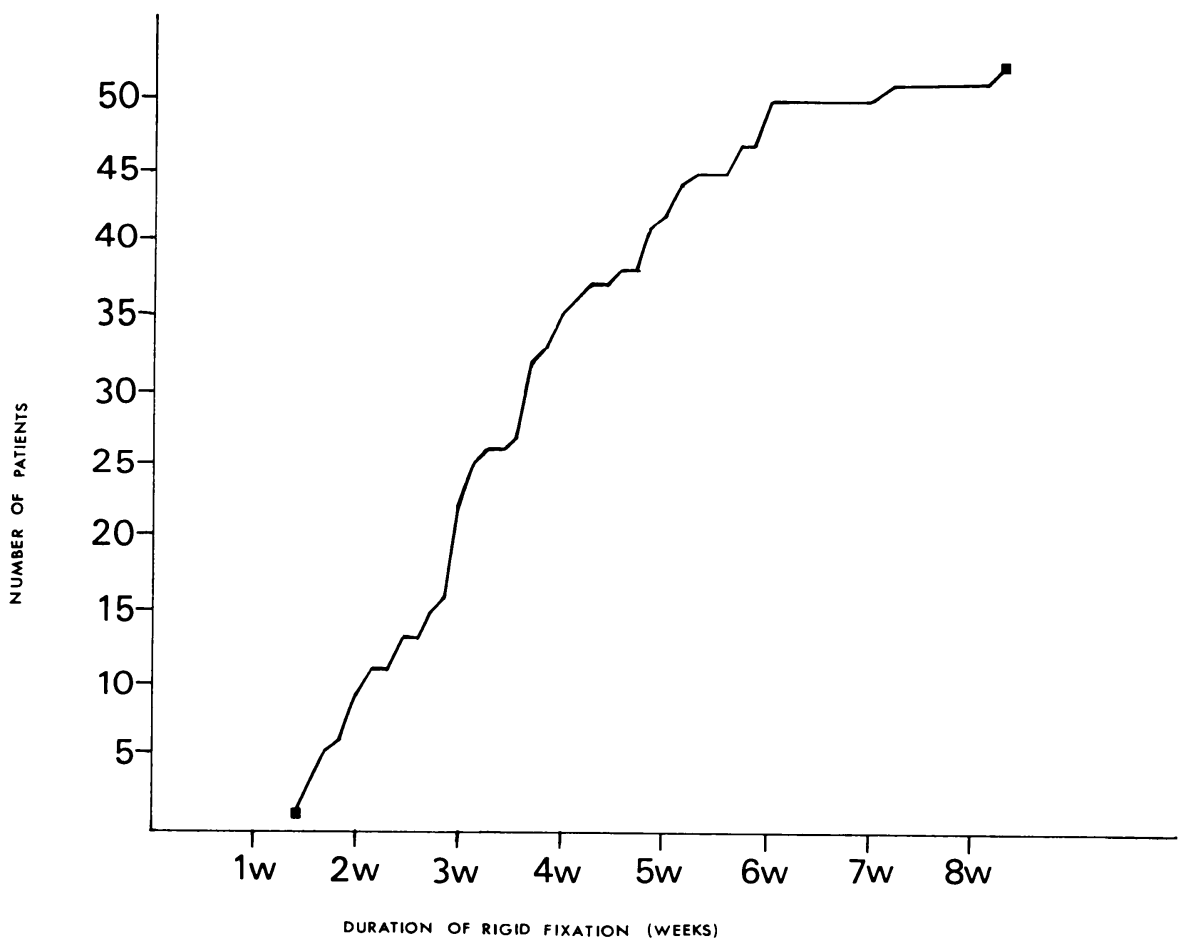

Fig. 3. Cumulative chart of duration of rigid fixation. Abscissa, time until removal of rigid fixation. Ordinate, cumulative number of cases with fixation removed.

average of 25.7 days. Of $35(67.3 \%)$ rigid maxillomandibular fixation cases, $22(42.3 \%)$ were released before 3 weeks and $13(25 \%)$ in the fourth week. In 17 patients $(32.7 \%)$ rigid fixation was used for more than 4 weeks (Fig. 3). Of the 52 rigid fixations, 31 (59.6\%) were followed by light elastic traction. During this time patients could open the mouth and move the mandible slightly, and could remove the elastic bands at mealtime. Light elastic traction was used for an average of 10.5 days. In the rigid maxillomandibular fixation group, complications occurred in $21.1 \%$ (11 cases). These were paresthesia of the inferior lip in 5 patients, malunion in 2 and malocclusion in 2 patients, one patient had preoperative infection and another had TMJ symptoms. 
Paresthesia and preoperative infection were diagnosed in 6 patients at the first examination. In only $5(9.6 \%)$ cases of this series was there any relation between the treatment and postoperative development of complications that could be attributed to the rigid maxillomandibular fixation (Table 2).

Of the 35 cases in which rigid fixation was released before 4 weeks, 4 patients developed postoperative complications (Table 2). In these 4 cases, it was found that complication developed in only one in whom fixation was released before 3 weeks. In the group in which rigid fixation was maintained for more than 4 weeks (17 patients) one malunion was found.

\section{Discussion}

In 1966, based on his clinical findings and studies on Macaca rhesus monkeys, Boyne ${ }^{5)}$ proposed the clinical practice of 4-week immobilization in oblique osteotomy of the mandibular ramus. Spector ${ }^{10)}$ in 1972 and Juniper and Awty ${ }^{8)}$ one year later, concluded that most fractures of the mandibular body require no more than 3 weeks of fixation. Chuong et al. ${ }^{6)}$ said that a four-week guideline for maxillomandibular fixation of fractures of the mandible is appropriate, and Amaratunga ${ }^{3)}$ reported in 1987 that the period of immobilization required is only 3-4 weeks in about $75 \%$ of patients.

Our results support these earlier reports. We found that of 52 patients who were treated by rigid fixation, $44.3 \%$ achieved clinical union before three weeks, $67.3 \%$ before four weeks, and only 17 patients $(32.7 \%)$ needed more than four weeks of fixation.

Histologic findings ${ }^{5)}$ sustained that there is bone change in areas of the condylar head during rigid maxillomandibular fixation, and clinical research") proved that mouth opening was reduced in patients treated by a long period of immobilization. For those reasons we limited the use of more than 4 weeks of fixation to cases in which there was originally great mobility at the fracture site.

The postoperative complication rate was very low: $9.6 \%$ of the total patients that received rigid fixation, and $11.4 \%$ of the group in which rigid fixation was released before 4 weeks. The procedure is technically simple and local anesthesia can be used in most cases. The duration of rigid fixation is determined by the movement between the fragments.

$\mathrm{Maw}^{9)}$ found in 1981 that $42 \%$ of a series of mandibular fractures were successfully treated without maxillomandibular fixation. His principal criteria for not utilizing maxillomandibular fixation was nondisplaced fragments. When there was no mobility or displacement at the fracture site we used semirigid fixation. Seven patients received semirigid fixation and sufferred no complications.

\section{Conclusions}

Three or four weeks of rigid maxillomandibular fixation is sufficient for clinical union in most uncomplicated mandibular fractures. Rigid fixation time depends on mobility at the fracture site. Semirigid fixation is applicable when there is no mobility or displacement at the fracture site.

\section{References}

1) Champy M, Lodde JP, Schmitt R, Jaeger JH and Muster D: Mandibular osteosynthesis by miniature screwed plates via a buccal approach. J Maxillofac Surg, 6: 14-21 (1978)

2) Winstanley RP: The management of fractures of the mandible. Br J Oral Maxillofac Surg, 22: 170-177 (1984) 
3) Amaratunga NA de S: The relation of age to immobilization period required for healing of mandibular fractures. J Oral Maxillofac Surg, 45: 111-113 (1987)

4) Amaratunga NA de S: Mouth opening after release of maxillomandibular fixation in fracture patients. J Oral Maxillofac Surg, 45: 383-385 (1987)

5) Boyne PJ: Osseous healing after oblique osteotomy of the mandibular ramus. J Oral Surg, 24: 125133 (1966)

6) Chuong R, Donoff RB and Guralnick WC: A retrospective analysis of 327 mandibular fractures. J Oral Maxillofac Surg, 41: 305-309 (1983)

7) James RB, Fredrickson C and Kent JN: Prospective study of mandibular fractures. J Oral Surg, 39: 275-281 (1981)

8) Juniper RP and Awty MD: The immobilization period for fractures of the mandibular body. Oral Surg, 36: 157-163 (1973)

9) Maw RB: A new look at maxillomandibular fixation of mandibular fractures. J Oral Surg, 39: 187-190 (1981)

10) Spector GJ: Early mastication in fractures of the body and angle of the mandible. Laryngoscope, 82: $1961-1970$ ( 1972)

11) Ueno T: Continuous interdental wiring for intermaxillary fixation. Dental Outlook, 19: 136-140 (1962) (in Japanese)

12) Yoshimasu H, Kashima $\mathrm{K}$ and Shioda S: New direct bonding bracket for oral surgery-Part 2 clinical application. Jpn J Oral Maxillofac Surg, 31: 1153-1156 (1985) (in Japanese)

[Received January 22, 1991: Accepted February 15, 1991] 